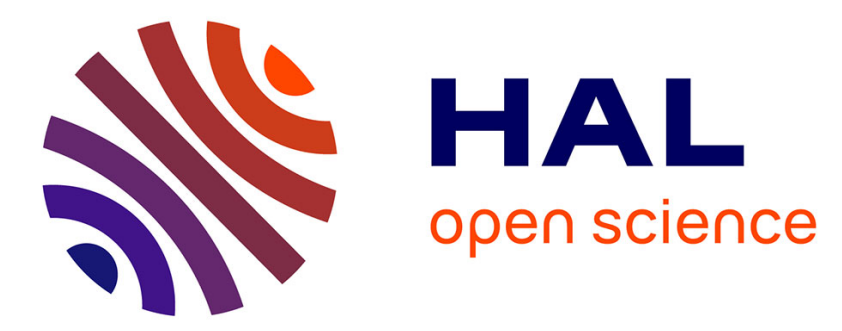

\title{
A novel stirred microcalorimetric cell for DSC measurements applied to the study of ice slurries and clathrate hydrates
}

Jean-Philippe Torre, Frédéric Plantier, Laurent Marlin, Rémi André, Didier Haillot

\section{To cite this version:}

Jean-Philippe Torre, Frédéric Plantier, Laurent Marlin, Rémi André, Didier Haillot. A novel stirred microcalorimetric cell for DSC measurements applied to the study of ice slurries and clathrate hydrates. Chemical Engineering Research and Design, 2020, 160, pp.465-475. 10.1016/j.cherd.2020.06.019 . hal-02884590

\section{HAL Id: hal-02884590 \\ https://hal.science/hal-02884590}

Submitted on 3 Dec 2020

HAL is a multi-disciplinary open access archive for the deposit and dissemination of scientific research documents, whether they are published or not. The documents may come from teaching and research institutions in France or abroad, or from public or private research centers.
L'archive ouverte pluridisciplinaire HAL, est destinée au dépôt et à la diffusion de documents scientifiques de niveau recherche, publiés ou non, émanant des établissements d'enseignement et de recherche français ou étrangers, des laboratoires publics ou privés. 


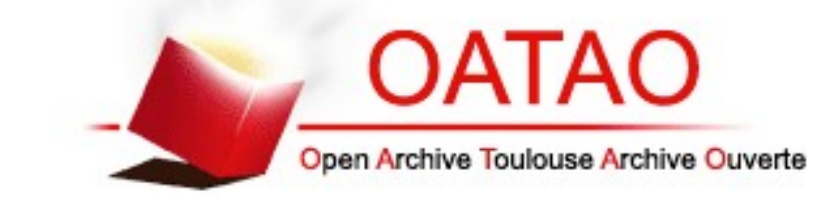

Open Archive Toulouse Archive Ouverte

OATAO is an open access repository that collects the work of Toulouse researchers and makes it freely available over the web where possible

This is an author's version published in:

http://oatao.univ-toulouse.fr/26988

\section{Official URL}

DOI : https://doi.org/10.1016/j.cherd.2020.06.019

To cite this version: Torré, Jean-Philippe $\leftrightarrows$ and Plantier, Frédéric and Marlin, Laurent and André, Rémi and Haillot, Didier A novel stirred microcalorimetric cell for DSC measurements applied to the study of ice slurries and clathrate hydrates. (2020) Chemical Engineering Research and Design, 160. 465-475. ISSN 0263-8762

Any correspondence concerning this service should be sent to the repository administrator: tech-oatao@listes-diff.inp-toulouse.fr 


\title{
A novel stirred microcalorimetric cell for DSC measurements applied to the study of ice slurries and clathrate hydrates
}

\author{
Jean-Philippe Torrée,*, Frédéric Plantier ${ }^{b}$, Laurent Marlin $^{c}$, Rémi Andréd, \\ Didier Haillot ${ }^{e, f}$ \\ a Laboratoire de Génie Chimique, Université de Toulouse, CNRS, INPT, UPS, Toulouse, France \\ b Université de Pau et des Pays de l'Adour, E2S UPPA, CNRS, TOTAL, LFCR, Anglet, France \\ c Université de Pau et des Pays de l'Adour, E2S UPPA, UPPA Tech - Atelier de Physique, 64013 Pau, France \\ d KEP Technologies Lyon, 7 Rue de l'Oratoire, CALUIRE, F-69300, France \\ e École de Technologie Supérieure, Département de génie mécanique, 1100, rue Notre-Dame Ouest, Montréal, \\ H3C1K3, Canada \\ ${ }^{\mathrm{f}}$ Université de Pau et des Pays de l'Adour, E2S UPPA, Laboratoire de Thermique, Énergétique et Procédés - IPRA, \\ EA1932, 64000 Pau, France
}

A R T I C L E I N F O

Keywords:

Calorimetry

Gas hydrates

DSC

Stirring

Mixing cell

Cyclopentane

\begin{abstract}
A B S T R A C T
A novel prototype of a microcalorimetric cell with in-situ stirring has been developed to perform DSC measurements under atmospheric or pressure conditions. After a brief technical description of the apparatus, preliminary tests are presented which analyzed the influence of the stirrer rotation on the heat-flow signal. Experiments were then performed with complex fluids such as ice slurries and clathrate hydrates formed with cyclopentane and with carbon dioxide. They took place in stirred and non-stirred conditions and the results obtained were then compared. It was proven that the rotation of the microstirrer in the measuring cell does not disrupt the heat-flow signal during the analysis. As regards the practical applications tested, the in-situ stirrer efficiently reduces crystallization metastability, increases the water-to-hydrate conversion, and reduces the amount of time needed for analysis. The dissociation enthalpy of cyclopentane (CP) hydrates was measured at atmospheric pressure; it is effectively very difficult to analyze this system with non-stirred calorimetry techniques because the two liquid phases are immiscible. The experimental results, in good agreement with other data found in the literature, showed complete water-to-CP hydrate conversion within a short period of time using a simple protocol. Experiments were also performed under pressure to demonstrate that $\mathrm{CO}_{2}$ hydrate phase equilibrium data could be obtained rapidly and easily. It is therefore our opinion that the potential of this novel technology has been thoroughly demonstrated.
\end{abstract}

1.

Introduction

Calorimetry, and more particularly Differential Scanning Calorimetry (DSC), is a highly sensitive and non-intrusive process used to detect

\footnotetext{
* Corresponding author.

E-mail address: Jean-philippe.Torre@ensiacet.fr (J.-P. Torré). https://doi.org/10.1016/j.cherd.2020.06.019
}

phase transitions, measure thermodynamic and thermophysical properties such as phase transition temperature, phase change enthalpy, reaction enthalpy or the heat capacity of various materials, and to monitor the kinetics of thermal events. The reader may refer to a number of books (Bennici and Auroux, 2009; Brown, 2001; Turi, 1997) and reviews (Ahmadi Khoshooei et al., 2019; Biliaderis, 1983) on the subject of calorimetry and DSC applications for detailed information and references. If the product to be analyzed is a pure substance or a homo- 
geneous mixture, it is relatively easy to measure its thermodynamical and thermophysical properties using a conventional calorimetric cell in which the material is left in static conditions during the experiment. For some applications though, such as studying energetic materials (Muravyeva et al., 2016), gas hydrates (Le Parlouër et al., 2004) or mimicking industrial process conditions (Pecchi et al., 2020), the calorimetric analysis must be performed under pressure. In the case of multiphase and complex mixtures, particularly if the analysis has to be done under pressure, the use of non-stirred calorimetric cells can pose serious limitations, such as long gas-in-liquid dissolution times, and homogeneity problems when emulsions, suspensions or fluids with complex rheology are used. In the case of crystallization and phase change materials in particular, nucleation in quiescent conditions is likely to require very long induction times due to the high metastability of the system studied, even if the temperature is reduced well below the fusion point of the material (Shao et al., 2019). The problem is even more complex when analyzing gas-liquid-solid systems under pressure, particularly in crystallization studies. In some cases, crystallization at the gas-liquid interface progressively forms a solid crust that prevents efficient gas dissolution in the liquid and limits the conversion rate if the liquid reacts (or interacts) with the gas. In such cases, analyses are made very difficult and time-consuming because of the absence of in-situ stirring in the calorimetric cell.

To overcome these limitations, the authors previously developed and patented a macro calorimetric cell $\left(\mathrm{V} \sim 8 \mathrm{~cm}^{3}\right)$ equipped with a mechanical stirrer and able to work under pressure (Torré et al., 2015b). This type of mixing cell was successfully used in a TianCalvet calorimeter (BT 2.15 model from SETARAM Instrumentation) and proved its efficiency, particularly for determining the thermophysical properties of gas hydrates (Delroisse et al., 2018; Plantier et al., 2013). However, in the past 30 years, the need arose for more sensitive, smaller-sample, and more flexible scanning calorimetry techniques, while new heat flow measurement systems such as Peltier elements became available. All this contributed to the development of the concept of micro Differential Scanning Calorimetry ( $\mu$-DSC), leading to a drastic reduction in equipment size and in the quantity of products needed for analysis. Miniaturizing the system greatly improved the global flexibility and versatility of the calorimeters; the use of Peltier elements instead of thermocouples helped increase the sensitivity of the methods, and improvements in terms of sample temperature control were also observed. However, the problem of maintaining the fluids under quiescent conditions during analysis still remained, particularly for measurements having to be performed under pressure, as until now, no technical solution had been put forward to ensure in-situ stirring in the $\mu$-DSC high pressure cells.

This paper therefore presents the potentialities of a novel type of microcalorimetric cell equipped with an in-situ mechanical stirrer. After a description of the technical apparatus, the influence of the stirring effect on the heat flux measured is discussed on the basis of preliminary runs. The efficiency of the apparatus is then demonstrated by studying two types of complex fluids for which crystallization and metastability problems frequently occur when using conventional analysis methods, i.e. unstirred cells: (i) ice slurry; (ii) clathrate hydrates (cyclopentane hydrates and $\mathrm{CO}_{2}$ hydrates).

Ice slurries are two-phase refrigerant fluids consisting of ice particles dispersed in water or in a water-based liquid aqueous solution. They appear to represent a very promising solution in the field of cold distribution networks (Kumar et al., 2019). By using ice slurry as a secondary fluid, it is possible to minimize the refrigerant charge in the primary cycle by dedicating it to cold production instead of transportation. It also allows the transportation of large quantities of latent cooling energy thanks to liquid solid phase change-related enthalpy (El Abbassi et al., 2014). In addition, ice slurry can be used in many direct contact food applications, in bakeries and fisheries for instance, but also for separation processes (Vaessen et al., 2003), or medical protective cooling applications to ensure protective hypothermia during heart surgery for example (Kauffeld et al., 2010). The mixing cell prototype presented in this article was first tested on ice slurry formed by crystallization of a water/ethanol mixture. The behavior of these solid-liquid systems had already been studied in our laboratory when we performed an energetic analysis of an entire cold network system, considering production and distribution (El Abbassi et al., 2010). For these tests, an initial solution containing $8.7 \%$ mass fraction of ethanol in water was chosen. At this concentration, the ice slurry presents two advantages: (i) it remains sufficiently fluid when ice particles crystallize, making it possible to test the stirring device without any risk of damage to the system due to blocking of the stirrer; (ii) the freezing point of the mixture, located on the liquidus curve at $-3.8 \pm 0.1{ }^{\circ} \mathrm{C}$ (Flick, 1998), is easily accessible with our apparatus. As a reminder for the reader, the liquidus equilibrium curve of a binary solution, such as the slurry studied here, represents the separation between singlephase and two-phase states. Above this curve, there is only a single liquid phase consisting of a solution of water and ethanol. Below this curve, two phases coexist: a solid phase consisting of pure ice, and a liquid phase of water and ethanol, which becomes more concentrated in alcohol as the temperature decreases. So, experiments were performed in quiescent and stirred conditions, following a protocol involving successive temperature cycles in order to test the apparatus and evaluate the effect of stirring on the crystallization of this system.

Clathrate hydrates are ice-like supramolecular solids formed by a network of water cages (the water is named the "host" molecule) stabilized by small "guest" molecules trapped within them (Sloan and Koh, 2008). Fundamental understanding of these compounds is crucial in many energy, process and environmental areas (Chong et al., 2016; Gholinezhad et al., 2011; Koh et al., 2011). The guest molecule forming the clathrate can be either liquid at atmospheric pressure (such as cyclopentane (CP), tetrahydrofuran or 1,3-dioxolane), or gaseous (such as $\mathrm{CO}_{2}, \mathrm{H}_{2} \mathrm{~S}, \mathrm{CH}_{4}$ ) forming what are known as "gas hydrates". These compounds are crystallized in specific thermodynamic conditions, which depend on the host-guest system, generally at low temperature (a few degrees above $0^{\circ} \mathrm{C}$ ), and under pressure (from a few bar to a few dozens of bar) for gas hydrates. Calorimetry techniques are essential for investigating the thermodynamic properties of hydrates and obtaining phase equilibrium data (Sum et al., 2009). A huge number of articles can be found in the literature concerning the use of DSC and $\mu$-DSC techniques applied to gas hydrates, such as the study of hydrate nucleation (Davies et al., 2009), effect of additives (Daraboina et al., 2011), cold storage in air-conditioning systems (Li et al., 2010), gas separation (Zhong et al., 2018), and hydrogen storage (Cai et al., 2019).

In some cases, measurements are severely limited due to the fact that the calorimetric cell (containing the sample to be analyzed) cannot be stirred. To overcome the limitations caused by quiescent conditions in the measuring cell, a succession of cooling and heating temperature cycles can be performed in order to progressively increase the water-tohydrate conversion from cycle to cycle. This method has been found to give reliable results, maximizing hydrate production by reducing, from cycle to cycle, the metastable phases (e.g. ice) that can affect the thermogram analysis (Deschamps and Dalmazzone, 2009, 2010; Martinez et al., 2008). However, the main drawbacks of this protocol are: (i) the time needed to complete all the temperature cycles, (ii) the formation of unwanted products, as the temperature must be sufficiently low in order to obtain a substantial driving force to break the high metastability of the system and succeed in crystallizing (iii) the solid crust formed at the liquid-gas interface that has a significant impact on kinetics and prevents efficient gas dissolution. In some cases, even when the protocol includes up to dozens of temperatures cycles, the systems might remain heterogeneous during the cooling phase (Sales Silva et al., 2016) and the water not completely converted to hydrates (Egenolf-Jonkmanns et al., 2017).

Cyclopentane (CP) hydrates can form at atmospheric pressure at temperatures below $\sim 6-8{ }^{\circ} \mathrm{C}$ (Ho-Van et al., 2019). Owing to this very interesting property, CP hydrates are considered as a model system for various studies and applications. For example, they are a good analog of natural gas hydrates for testing the effects of different types of chemical additives (e.g. anti-agglomerants) for flow assurance purposes in oil and gas production (Abojaladi and Kelland, 2016; Dicharry et al., 2020). $\mathrm{CP}$ is lighter than water (density of $0.7457 \mathrm{~g} \mathrm{~cm}^{-3}$ at $20^{\circ} \mathrm{C}$ ) (Haynes, 2013), is almost immiscible in water (156 ppm at $25^{\circ} \mathrm{C}$ ) (Yalkowsky et al., 2010), and water/CP systems always have two liquid phases at atmospheric pressure. In addition, CP has a vapor pressure of $0.437 \mathrm{bar}$ 
at $25^{\circ} \mathrm{C}$ (Kay, 1947), which makes it a very volatile organic compound. Due to the fact that $\mathrm{CP}$ hydrates crystallize at the $\mathrm{CP} /$ water interface, it can be very difficult to get a large quantity of $\mathrm{CP}$ hydrates to form in quiescent conditions, particularly when no additives (e.g. surfactants) are added to the system (Delroisse et al., 2017; Taylor et al., 2007). To overcome this substantial limitation, it is possible to work with an emulsion formed before the calorimetry experiment. The main advantages of this emulsification technique are: (i) the possibility of achieving high hydrate conversion rates by significantly increasing the water-CP interfacial area, and (ii) of limiting $\mathrm{CP}$ evaporation as the droplets of $\mathrm{CP}$ (forming the dispersed phase) are surrounded by water (forming the continuous phase). However, this protocol also has some severe drawbacks: (i) there has to be an additive (e.g. a surfactant) in the system to stabilize the emulsion, and (ii) residual unconverted liquid might be present at the core of the droplets. In this study, comparative experiments were performed with this system in quiescent and stirred conditions, to observe the effect of stirring on the results obtained and to provide an estimation of the dissociation enthalpy of $\mathrm{CP}$ hydrates. Indeed, this value has hardly ever been debated in the hydrate scientific community (Delroisse et al., 2018; Lee et al., 2019; Nakajima et al., 2008; Zhang et al., 2004).

Lastly, the cell prototype was tested under pressure with $\mathrm{CO}_{2}$ and water to study $\mathrm{CO}_{2}$ hydrates. We chose this system as its properties are well known (Circone et al., 2003; Uchida, 1997; Uchida et al., 1995), and $\mathrm{CO}_{2}$ hydrates are promising candidates for potential engineering applications such as carbon capture (Kumar et al., 2015) and secondary refrigeration (Oignet et al., 2017). Note that, when the gas used to form hydrates is $\mathrm{CO}_{2}$, an additional advantage of maintaining the temperature above $0{ }^{\circ} \mathrm{C}$ during the analysis is that it avoids the liquefaction of $\mathrm{CO}_{2}$ at low temperature. The aim of the experiments carried out was to verify the following three points: (i) is the set-up suitable for studying the formation of gas hydrates under pressure?; (ii) could the stirred system trigger hydrate formation under pressure at temperatures greater than $0{ }^{\circ} \mathrm{C}$ to avoid ice formation (which is usually an issue when using conventional measurement cells)?; and (iii) is one temperature cycle sufficient to obtain a point on the $\mathrm{CO}_{2}$ hydrate phase equilibrium diagram (i.e. the hydrate dissociation temperature which corresponds to the constant pressure of the experiment)?

\section{Experimental section}

\subsection{Description of the experimental apparatus}

Fig. 1 shows a diagram of the stirred calorimetric cell prototype, and Fig. 2 presents general views of the apparatus.

As shown in Figs. 1 and 2a, the upper part of the device is the stirring motor. The stirring shaft, fixed on a permanent magnet and connected to the motor by a magnetic coupling, runs through the fluid injection section with gas inlet/outlet fittings, and reaches the measuring cell located at the bottom of the prototype. A flat paddle (Fig. $2 b$ ) made in-house is connected to the end of the shaft for stirring the fluids contained in the measuring cell. In the middle section, the stirring shaft runs through a tube made of stainless steel used to circulate the fluids in the system from the injection section to the measuring cell. The whole set-up can withstand pressures of up to 150 bar. The stirrer's rotational speed was measured under atmospheric conditions using a photo tachometer (Lutron DT 2259 with a precision of $\pm 1 \mathrm{rpm}$ ). A linear relationship was found between the voltage $(\mathrm{V}$, in volts) and the rotational speed $(\omega$, in rpm) up to $2000 \mathrm{rpm}$, satisfying Eq. 1 from $\mathrm{V}=1.53 \mathrm{~V}(\omega$ $=186 \mathrm{rpm})$ up to $\mathrm{V}_{\max }=10.7 \mathrm{~V}(\omega=2054 \mathrm{rpm})$ :

$\omega=203,7 \mathrm{~V}-125,6$

The usable volume of the measurement cell (Fig. 2c) - considering the volume of the stirrer and the liquid level limit

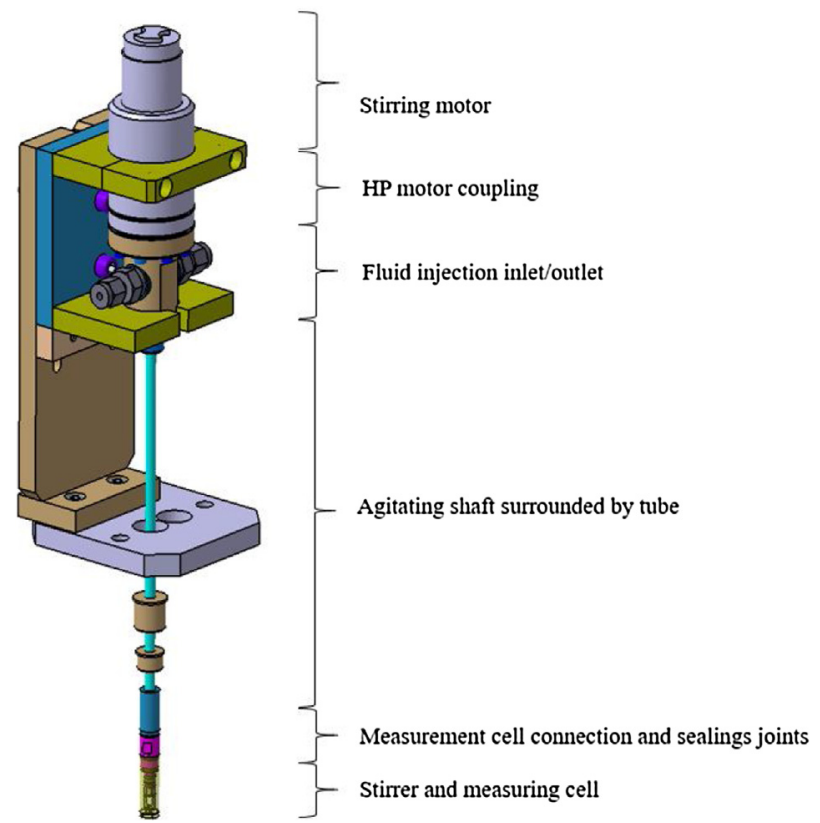

Fig. 1 - Diagram of the prototype.

at the top of the stirrer - is $0.213 \mathrm{~cm}^{3}$. The total sample volume of the apparatus (i.e. the volume of the measurement cell with the stirrer, the tube through which runs the shaft, the fluid injection section, and the dead zones of the inlet/outlet fittings) is $2.1 \pm 0.1 \mathrm{~cm}^{3}$.

The stirred calorimetric cell prototypes presented in this study are used with a Setaram Instrumentation $\mu$ DSC7 evo device made by KEP Technologies. The apparatus features a Calvet three-dimensional sensor with Peltier elements and is calibrated by Joule effect. The cells are heated and cooled owing to a two-stage liquid thermostat also with Peltier elements. Just as standard DSCs, the $\mu$ DSC7 has two cells (a measurement cell and a reference one) in order to correct the heat flow signal measured for most thermal effects related to the cells. During experiments (e.g. measuring a thermophysical property of a complex fluid, a phase change transition temperature, etc.), the cell prototype is placed in the measurement well of the calorimeter (Fig. 2d), while another cell (this one without a stirring system and containing only Nitrogen) is placed in the reference well. To obtain only the thermal response of the sample of interest, the flow measurement of the measuring cell is subtracted from that of the reference cell. The operational temperature of the $\mu \mathrm{DSC} 7$ ranges between $-45^{\circ} \mathrm{C}$ and $120^{\circ} \mathrm{C}$, while its programmable temperature scanning rate ranges between 0.001 and $2{ }^{\circ} \mathrm{C} \mathrm{min}{ }^{-1}$. Finally, the measuring cell is connected to a high-pressure panel equipped with a digital manometer (Keller, model Leo II) with an accuracy of \pm 0.1 bar. The panel comprises a pressure-reducing valve to pressurize the cell, coupled with a $300 \mathrm{~cm}^{3}$ buffer vessel which is always connected to the cell. This system relies on the large volume difference between the buffer vessel and the cell to maintain a constant pressure in the cell and make up for most pressure variations during the experiments.

For calorimetric measurements such as phase transition temperature and associated enthalpy change, meticulous temperature and enthalpy calibrations are required. Although the Peltier heat flux sensor elements of the $\mu \mathrm{DSC7}$ evo calorimeter are pre-calibrated by the supplier, two high-purity standards (n-tetradecane and hexadecane) and water were analyzed to make sure that the calibration was correct and 


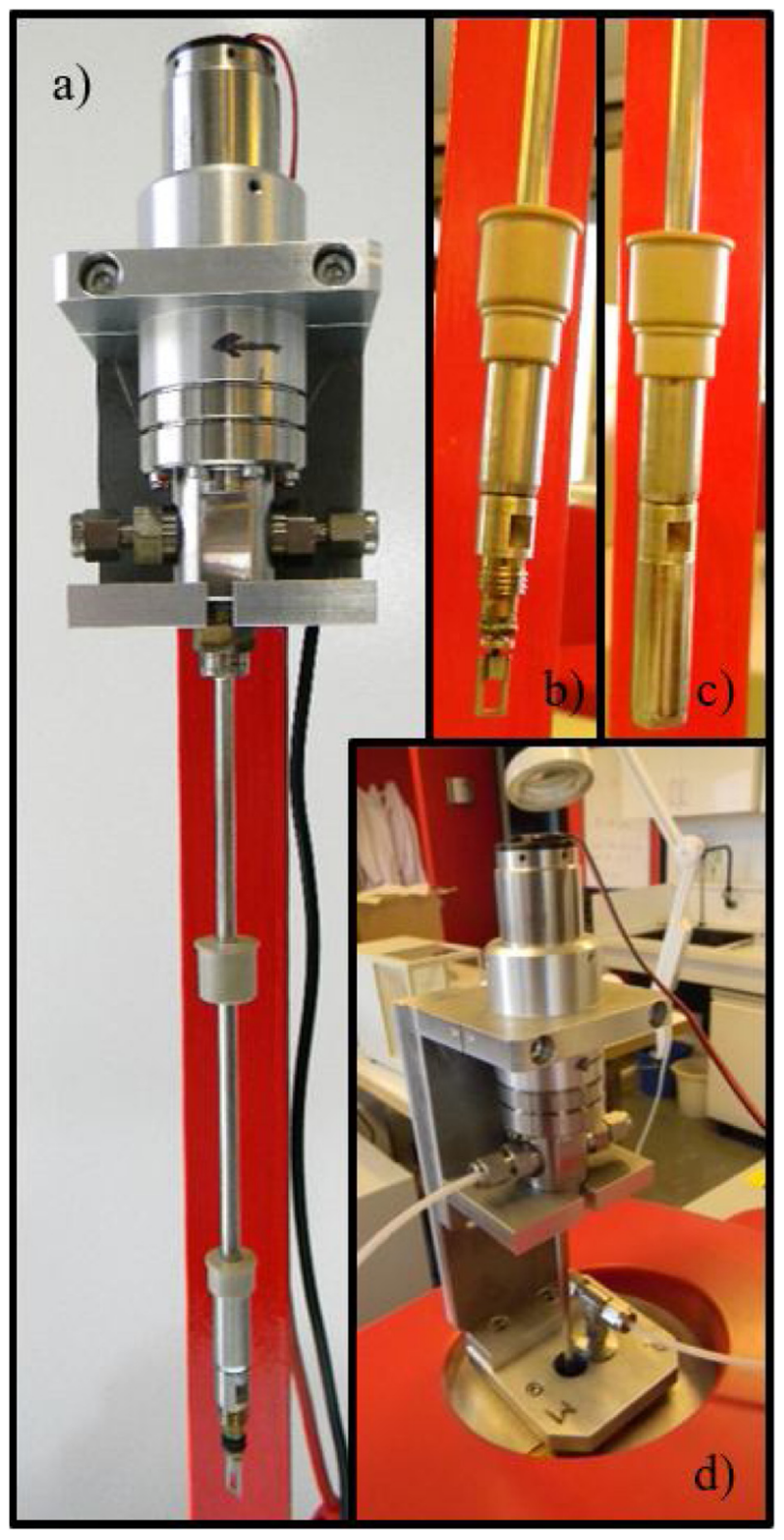

Fig. 2 - Photographs of the prototype: a) full prototype, b) zoom-in on the stirrer and c) the measuring cell before the experiment, d) prototype placed on a Setaram $\mu \mathrm{DSC7}$ evo calorimeter.

did not drift over time. Comparison of experimental and reference data obtained from the literature served to validate the calibration parameters of the calorimeter, and absolute uncertainties of $\pm 0.2^{\circ} \mathrm{C}$ and $\pm 10 \mathrm{~J} \mathrm{~g}^{-1}$ were considered for the phase transition temperature and enthalpy change respectively.

\subsection{Materials}

The materials used for the experiments presented in section III are compiled in Table 1.

The cells and the materials loaded into the cell were weighed using a precision balance (Mettler Toledo XP26 model) with an accuracy of $0.004 \mathrm{mg}$.

\subsection{Preliminary tests}

Because this type of microcalorimetric cell containing a mechanical stirrer had never been tested before, it was
Table 1 - materials used, suppliers and purities.

\begin{tabular}{lll} 
Material & Supplier & Purity \\
\hline Carbon dioxide & Air Liquide & $\geq 99.7 \%$ \\
Cyclopentane & Acros Organics & $>98 \%$ \\
Ethanol & Fluka Analytical & $\geq 99.8 \%$ \\
Hexadecane & Sigma Aldrich & $\geq 99 \%$ \\
n-Tetradecane & Sigma Aldrich & $\geq 99 \%$ \\
Water & Purelab system & - \\
\hline
\end{tabular}

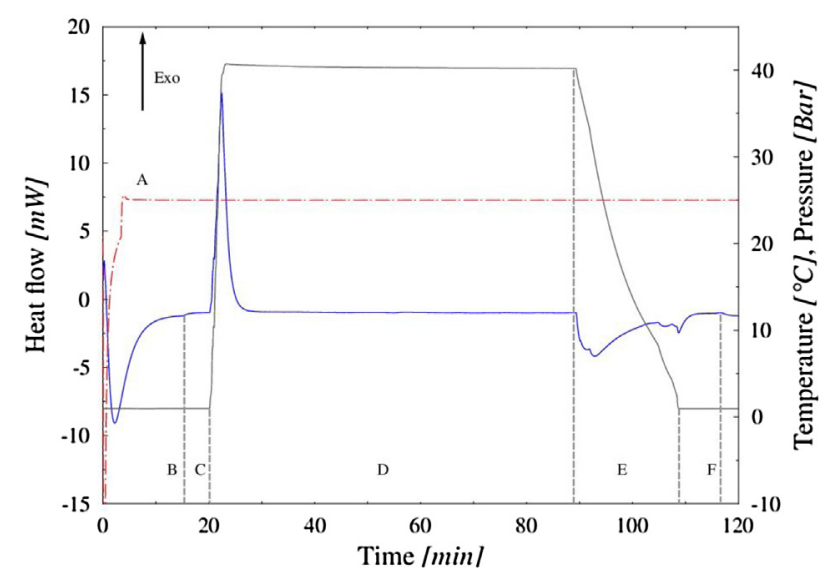

Fig. 3 - Influence of stirring in an empty measuring cell under pressure. Heat flow: full blue line; temperature: dot-dashed red line; cell pressure: full gray line; letters A to F: characteristic steps or events cited in the text; the vertical dashed lines are visual guidelines.

thought that the rotation of a mechanical element in the measuring cell might disrupt the thermal response (e.g. signal noise). This section therefore presents the results of preliminary tests carried out before any analyses and calculations, to answer the following question: does the mechanical stirring affect the stability of the heat flux baseline during the DSC analysis?

At first, the influence of the stirrer rotation was tested at pressure, without any liquid loaded in the measuring cell. The evolution of the heat flux versus time is shown in Fig. 3.

Throughout the experiment, the temperature is stabilized at $25{ }^{\circ} \mathrm{C}$ (Fig. 3A). At time $\mathrm{t}=17 \mathrm{~min}$, the stirrer is switched on (Fig. 3B) at a rotational speed of $490 \mathrm{rpm}$. The heat flow increases very slightly and then rapidly stabilizes (in $\sim 1 \mathrm{~min}$ ). The pressure of the cell is then set to 40.0 bar (Fig. 3C) with $\mathrm{CO}_{2}$. As a logical consequence, an exothermic peak related to gas compression is then measured. Temperature and pressure are then stabilized for one hour, from $t=20 \mathrm{~min}$ to $t \approx 90 \mathrm{~min}$, while the stirrer is in operation (Fig. 3D). During this time, the heat flow measured is perfectly stable, which indicates that the rotation of the stirrer does not disrupt the heat flow measurement. The gas decompression step (Fig. 3E) exhibits an inverse behavior to the compression step and generates an endothermic peak as can be seen on the thermogram, followed by heat flow equilibrium at $t=108 \mathrm{~min}$. The stirrer is switched off at $\mathrm{t}=117 \mathrm{~min}$ : the heat flow decreases slightly and stabilizes at a constant value identical to the one reached before the stirrer was started (Fig. 3F).

The second test consisted in performing the same experiment but with liquid in the cell. In this experiment, the cell was filled with $0.047060 \mathrm{~g}$ of water. The experimental protocol is essentially identical to the one described in the previous paragraph, and the results obtained are presented in Fig. 4. The temperature is first stabilized at $25^{\circ} \mathrm{C}$ before stirring starts at 


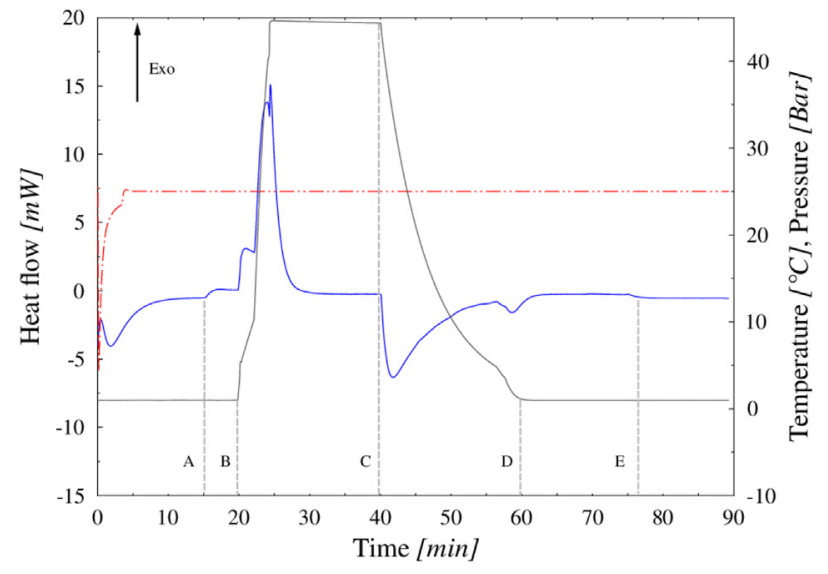

Fig. 4 - Influence of stirring in a measuring cell under pressure and filled with water. Heat flow: full blue line; temperature: dot-dashed red line; cell pressure: full gray line; letters A to E: characteristic steps or events cited in the text; the vertical dashed lines are visual guidelines.

$\mathrm{t}=15 \mathrm{~min}$ (Fig. 4A). Then, at $\mathrm{t}=20 \mathrm{~min}$, the cell is pressurized by $\mathrm{CO}_{2}(\mathrm{P}=44.0 \mathrm{bar})$, producing an exothermic peak (Fig. 4B) due to compression of the gas. In short, from $t=20$ min to $t$ $=40 \mathrm{~min}$, the cell is under pressure, contains water, and the mechanical stirrer is rotating at $490 \mathrm{rpm}$. Consequently, even with liquid in the cell, the stirring does not induce any measurement noise. To finish, the cell is decompressed (leading to an endothermic signal) at $\mathrm{t}=40 \mathrm{~min}$ (Fig. $4 \mathrm{C}$ ), returned to atmospheric pressure (Fig. 4D) at $\mathrm{t}=60 \mathrm{~min}$ and the stirrer is stopped at $\mathrm{t}=77 \mathrm{~min}$ (Fig. $4 \mathrm{E}$ ). It can be concluded, from the slight drifts observed on the thermograms for $\mathbf{A}$ and $\mathrm{E}$ events, that the starting and stopping of the stirrer induce only small, insignificant variations in the heat flow signal.

The two tests, performed under pressure with and without liquid in the cell, demonstrated that this type of system, comprising a mechanical stirrer rotating in a microcalorimetric cell, does not cause any disruption of or signal noise (e.g. a perfectly stable baseline is obtained) on the heat flux measured over time, even in pressure conditions.

\subsection{Experiments with ice slurry}

To perform comparative experiments and illustrate the effects of in-situ stirring, $\sim 0.05 \mathrm{~g}$ of the ethanol/water mixture (8.7 wt\% of ethanol) were carefully introduced into the measuring cell. The analysis was conducted first without stirring, then with continuous stirring at a rate of $490 \mathrm{rpm}$. The following experimental protocol was applied: the ethanol/water mixture was maintained at $10^{\circ} \mathrm{C}$ for $15 \mathrm{~min}$, the temperature was reduced to $-15^{\circ} \mathrm{C}$ at $0.5^{\circ} \mathrm{C} \mathrm{min}-1$, and the system was stabilized for $15 \mathrm{~min}$ at this temperature. The system was then heated at $0.5{ }^{\circ} \mathrm{C} \mathrm{min}^{-1}$ to return to the initial temperature of $10{ }^{\circ} \mathrm{C}$. This cooling/heating cycle was performed successively 6 times, and the results were analyzed at the end of the cycles.

\section{5. $\quad$ Experiments with clathrate hydrates}

\subsubsection{Cyclopentane hydrates}

All the experiments with CP hydrates involved an excess amount of $\mathrm{CP}$, with respect to the stoichiometric amount of water and CP necessary to form CP hydrates (usually called "excess CP protocol" in opposition to the case where an excess amount of water is used). The $\mathrm{CP}$ excess protocol has two main advantages: (i) it is easy to verify whether a full water-tohydrate conversion is obtained, (ii) and because there is always a quantity of liquid CP present during the experiment, this ensures that the gas phase is always saturated with CP. As it takes one mole of CP per $17 \mathrm{~mol}$ of water for cyclopentane hydrates (formula $\mathrm{CP}-17 \mathrm{H}_{2} \mathrm{O}$ ) to form, it is easy to determine the stoichiometric quantities of phases necessary to ensure $\mathrm{CP}$ hydrate formation. However, as CP is a highly volatile organic compound, a sufficient excess amount of CP (relative to the exact stoichiometric quantity of $\mathrm{CP}$ required to form the $\mathrm{CP}$ hydrates) must always be introduced into the cell to guarantee that full water-to-hydrate conversion will be achieved. In the experiments presented below, we always worked with cold water and $\mathrm{CP}\left(\sim 8-10^{\circ} \mathrm{C}\right)$ to limit evaporation as much as possible when preparing the sample, and used a molar excess of $\mathrm{CP}$ (in relation to the stoichiometric value) of $15-30 \%$. Considering the total gas volume of the apparatus and the vapor pressure of $\mathrm{CP}$ at $25^{\circ} \mathrm{C}$ (initial and maximum temperature in the protocol), we calculated that less than $10 \%$ of the CP initially introduced into the cell vaporizes to saturate the gas phase, which always leaves a minimum of $5 \%$ excess liquid CP (in relation to the stoichiometric value) during the experiments.

A very simple protocol was used to illustrate the potential of the apparatus and assess the effect of stirring. The temperature profile was programmed as follows: the temperature was first decreased (in quiescent conditions) from $25^{\circ} \mathrm{C}$ to -40 ${ }^{\circ} \mathrm{C}$ at $1{ }^{\circ} \mathrm{C} \mathrm{min}^{-1}$ (to force the system to crystallize), before being increased to $+1{ }^{\circ} \mathrm{C}$ (with the same temperature ramp) and maintained for $6 \mathrm{~h}$ at this temperature. At the end of the $+1{ }^{\circ} \mathrm{C}$ temperature plateau, before increasing the temperature to $25^{\circ} \mathrm{C}$, we chose to decrease the temperature to $-10{ }^{\circ} \mathrm{C}$ to check for the presence of any unconverted water: if there were any free water in the cell, it would crystallize during this cooling step, leading to an exothermic peak on the thermogram (this step could be avoided by reducing the time of analysis for routine measurements, as it is just a way of checking whether or not unconverted water is present). Finally, the temperature was increased from $-10{ }^{\circ} \mathrm{C}$ to $25^{\circ} \mathrm{C}$ at $0.1^{\circ} \mathrm{C} \mathrm{min}{ }^{-1}$ to melt the crystals formed and measure the dissociation temperature and enthalpy of the CP hydrates. The phase transition temperature correlated with the heat flow signals obtained during the final heating step make it possible to identify the nature of the crystals formed: $\sim 0{ }^{\circ} \mathrm{C}$ for ice, and $\sim 7^{\circ} \mathrm{C}$ for the $\mathrm{CP}$ hydrates. The experiments were repeated twice for non-stirred conditions, and four times for stirred conditions.

\subsection{2. $\mathrm{CO}_{2}$ hydrates}

In these experiments, the temperature varied between $20^{\circ} \mathrm{C}$ and $0.8{ }^{\circ} \mathrm{C}$. The pressure level was chosen so that the $\mathrm{CO}_{2}$ would remain in its gaseous state: as the liquefaction pressure of $\mathrm{CO}_{2}$ at $0{ }^{\circ} \mathrm{C}$ is 34.85 bar (Anwar and Carroll, 2011), the operating pressure was set slightly below this at $33.0 \pm 0.5$ bar. Additionally, this is an ideal operating point (i.e. 33 bar, 0.8 $\left.{ }^{\circ} \mathrm{C}\right)$ to maximize the driving force for crystallization, which, at constant pressure, corresponds to the subcooling temperature (i.e. the distance between the hydrate equilibrium temperature and the experimental set point). Note that, at $\sim 33$ bar, the $\mathrm{CO}_{2}$ hydrate equilibrium temperature given by the Colorado School of Mines Hydrate Prediction Program CSMGem V1.10 (Sloan and Koh, 2008) is $7.8^{\circ} \mathrm{C}$, corresponding to a subcooling of $\sim 7^{\circ} \mathrm{C}$. Note that, in the conditions of this study, the excellent agreement between experimental values and numerical $\mathrm{CO}_{2}$ hydrate equilibrium data predictions obtained from CSMGem 


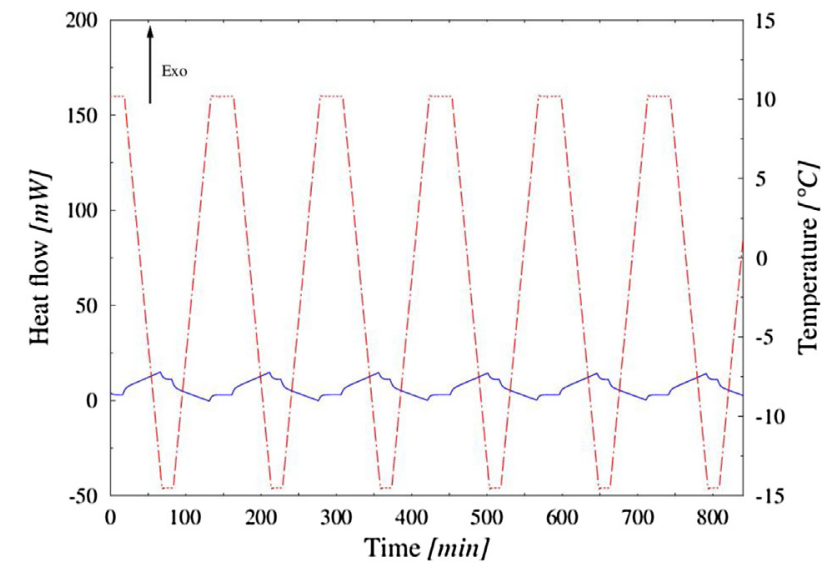

Fig. 5 - Thermogram obtained for a water/ethanol mixture at $8.7 \mathrm{wt} \%$ without stirring in the cell. Heat flow: full blue line; temperature: dot-dashed red line.

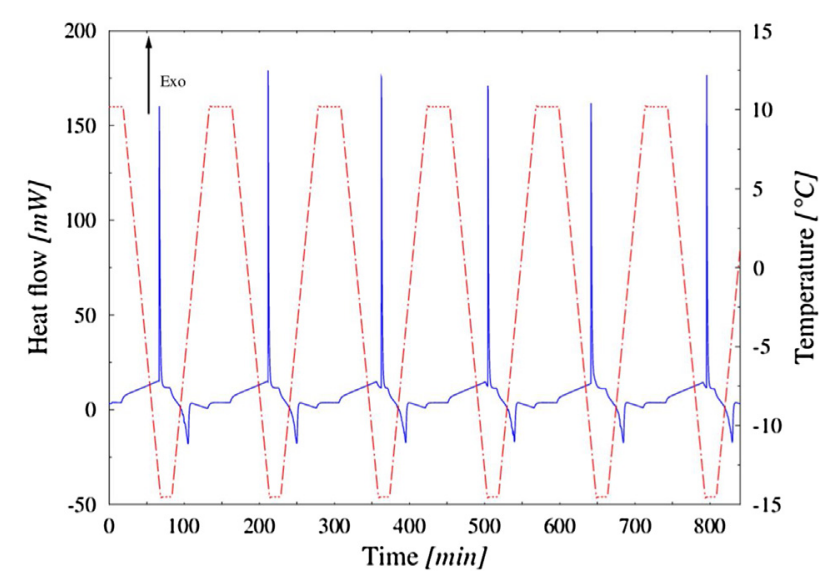

Fig. 6 - Thermogram obtained for a water/ethanol mixture at $8.7 \mathrm{wt} \%$ with stirring in the cell. Heat flow: full blue line; temperature: dot-dashed red line.

have already been demonstrated by the authors in a previous article (Torré et al., 2015a).

The following experimental protocol is typically used: a mass of water $\sim 0150 \mathrm{~g}$ is first introduced and precisely weighed in the measurement cell. The cell is closed, inserted into the calorimeter and connected to the gas panel. The system is flushed at least three times with $\mathrm{CO}_{2}$ to eliminate any traces of air. Approximately ten minutes after the beginning of the experiment, the cell is pressurized with $33 \pm 0.5$ bar of $\mathrm{CO}_{2}$. The only difference between the two sets of experiments is a stirring period of $100 \mathrm{~min}$. Concerning the temperature profile, the cell is first regulated at $20^{\circ} \mathrm{C}$ for $40 \mathrm{~min}$, before the temperature is decreased to $0.8^{\circ} \mathrm{C}$ at $1^{\circ} \mathrm{min}^{-1}$ and stabilized for $40 \mathrm{~min}$. It is then increased again to $20^{\circ} \mathrm{C}$ as per the same temperature ramp and finally stabilized at $20^{\circ} \mathrm{C}$. Four experiments were carried out for each condition (i.e. quiescent and stirred) using the same protocol to check reproducibility.

\section{Results and discussion}

\subsection{Ice slurry}

Figs. 5 and 6 show the thermograms obtained in quiescent and stirred conditions respectively.

With the protocol used, an exothermic peak related to the solidification of the water should be observed during the cooling phases (as the temperature set point of $-15^{\circ} \mathrm{C}$ is far beyond the liquidus point of $\sim-4{ }^{\circ} \mathrm{C}$ ) followed by an endothermic peak during heating corresponding to the fusion of the ice formed. Fig. 5 shows that this is not the case in quiescent conditions for any of the six temperature cycles, demonstrating the high metastability of this system (i.e. the ice is not crystallizing even though the temperature is well below the freezing point of the mixture), and consequently, the difficulty of analyzing it in these conditions. On the contrary, in stirred conditions, the crystallization and fusion events occur in all the cycles as shown in Fig. 6. Accordingly, the liquidus temperature is then measured at the top of the fusion peak (progressive transformation) and equals $4.0 \pm 0.2^{\circ} \mathrm{C}$, which is in perfect agreement with the value of $-3.8 \pm 0.1{ }^{\circ} \mathrm{C}$ mentioned in the literature (Flick, 1998). These simple experiments demonstrate that the micro stirrer rotating in the cell is very efficient for promoting nucleation and enhances the crystallization by easily breaking the subcooling effect.

\subsection{Clathrate hydrates}

\subsubsection{Cyclopentane hydrates}

Two typical thermograms obtained in quiescent $(0.105290 \mathrm{~g}$ of water, $0.030310 \mathrm{~g}$ of $\mathrm{CP}, 20 \%$ excess molar volume of $\mathrm{CP}$ in relation to the hydrate stoichiometry) and stirred conditions ( $0.10590 \mathrm{~g}$ of water, $0.02841 \mathrm{~g}, 15 \%$ molar volume excess of $\mathrm{CP}$ in relation to the hydrate stoichiometry) are presented in Figs. 7 and 8 respectively. Two additional thermograms (see Fig. S1 and S2 of Supporting Information) show the very good reproducibility of the measurements in each condition.

In the typical experiment shown in Fig. 7, the system is left in quiescent conditions (i.e. stirrer off all the time). In the first cooling step, crystallization is observed at $\sim-20^{\circ} \mathrm{C}$, corroborated by the sharp exothermic peak measured on the heat flow curve (point A in Fig. 7a). In the following heating step, the fusion of the crystals formed at low temperature is revealed by the endothermic peak on the heat flow curve (point B in Fig. 7a). In the second cooling step (occurring at the end of the $+1{ }^{\circ} \mathrm{C}$ plateau), the sharp exothermic peak observed on the heat flow curve is again directly correlated with a crystallization process (point C in Fig. 7a). In the final heating step, two peaks are visible as shown in Fig. 7b: a very large peak (marked with a single asterisk) and a very small one (marked with a double asterisk). As the onset temperature of the first peak is $0.1{ }^{\circ} \mathrm{C} \pm 0.2$, this phase transition indubitably corresponds to the fusion of ice. Concerning the phase transition corresponding to the tiny endothermic bump noted on the thermogram at around $6-8{ }^{\circ} \mathrm{C}$ (the onset temperature and the surface of this peak cannot be measured precisely as the peak is too small), it can be attributed to the dissociation of a very small quantity of hydrates formed with ice in the last crystallization step (Zhang et al., 2004) or in the heating step when the ice begins to melt (Fouconnier et al., 2006; Karanjkar et al., 2012a). The thermogram obtained in quiescent conditions is perfectly reproducible as shown in Fig. S1 of Supporting Information. As a matter of fact, this protocol without stirring is not appropriate for producing large quantities of CP hydrates, and confirms that it is very difficult to obtain $\mathrm{CP}$ hydrates in static conditions without using an additive.

In the typical experiment presented in Fig. 8, the system is first left in quiescent conditions for the first cooling and heating ramps to initiate crystallization. As expected, the same observations as in Fig. 7 can be made for this temperature cycle: crystallization is initially observed in the first cooling step (exotherm at point A), and the fusion of the crystals takes 
(a)

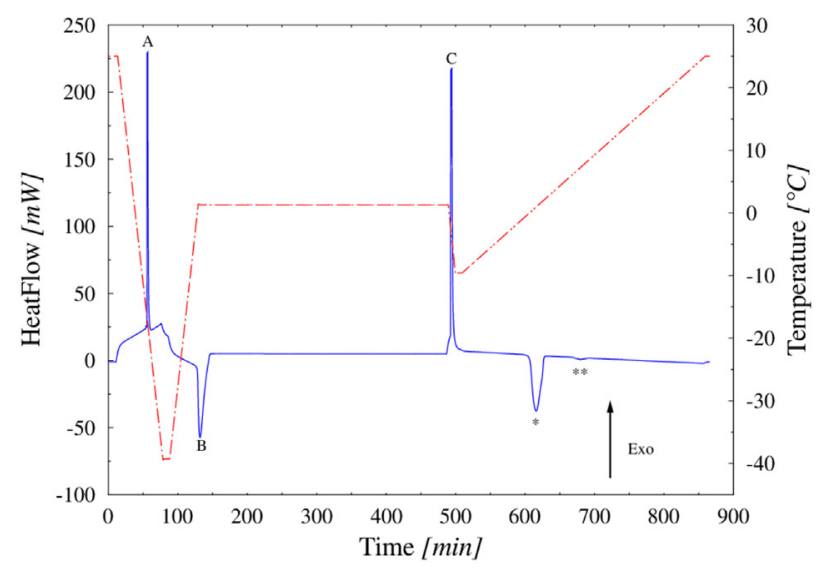

(b)

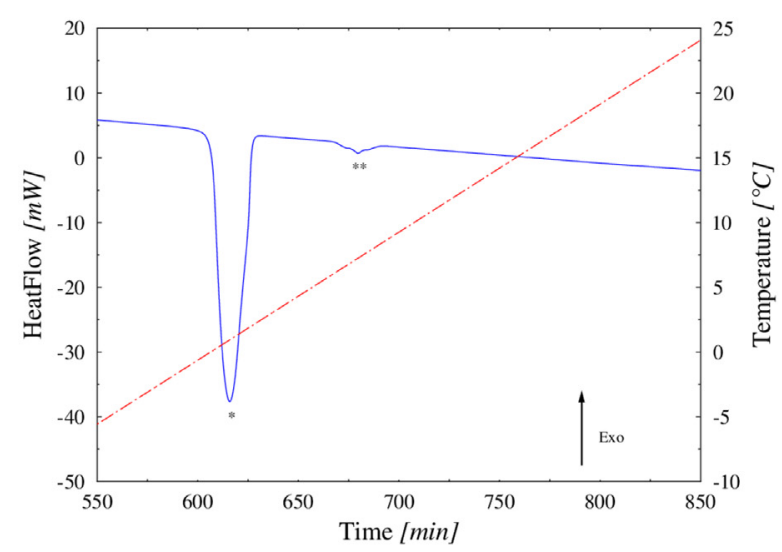

Fig. 7 - Thermogram of a CP hydrate formation experiment without stirring in the cell. Heat flow: full blue line; temperature: dot-dashed red line; symbol *: ice fusion; symbol **: CP hydrate dissociation; letters A, B, C: characteristic events discussed in the text; (a) full thermogram; (b) zoom-in on the last heating cycle.

place in the first heating step (endotherm at point B). The stirrer in the calorimetric cell is then switched on, a few minutes after the temperature is stabilized at $+1^{\circ} \mathrm{C}$ (i.e. at the beginning of the temperature plateau, at point $\mathrm{C}$ ). The system is maintained in stirring conditions for $90 \mathrm{~min}$ at a rotational speed of $1504 \mathrm{rpm}$, and the stirrer is then switched off at point E. During this short stirring step, a strong exothermic peak can clearly be seen on the heat flow curve (point D). Because the temperature of the cell is $+1^{\circ} \mathrm{C}$ (i.e. above the fusion temperature of ice and below the equilibrium temperature of $\mathrm{CP}$ hydrates), this peak cannot be attributed to ice crystallization, but to the formation of $\mathrm{CP}$ hydrates. Interestingly enough, the final temperature ramp (from -10 to $25^{\circ} \mathrm{C}$ ) exhibits only one endothermic peak (marked with a double asterisk), with a $\mathrm{T}_{\text {onset }}=6.6 \pm 0.2$. Note that the small peak observed in the cooling step from $+1{ }^{\circ} \mathrm{C}$ to $-10{ }^{\circ} \mathrm{C}$ at the end of the temperature plateau (point F) is a typical DSC artifact caused by the transient heat flux generated by the sensor response during the change of heating sequence, and not by ice crystallization; the heat flux is effectively perfectly flat close to $0{ }^{\circ} \mathrm{C}$ during the final heating ramp as clearly shown in Fig. 8b. The thermogram obtained in stirred conditions is perfectly reproducible as can be seen in Fig. S2 of Supporting Information. It can therefore be concluded that this simple protocol is very efficient for forming CP hydrates, with full conversion of the water into CP hydrates. (a)

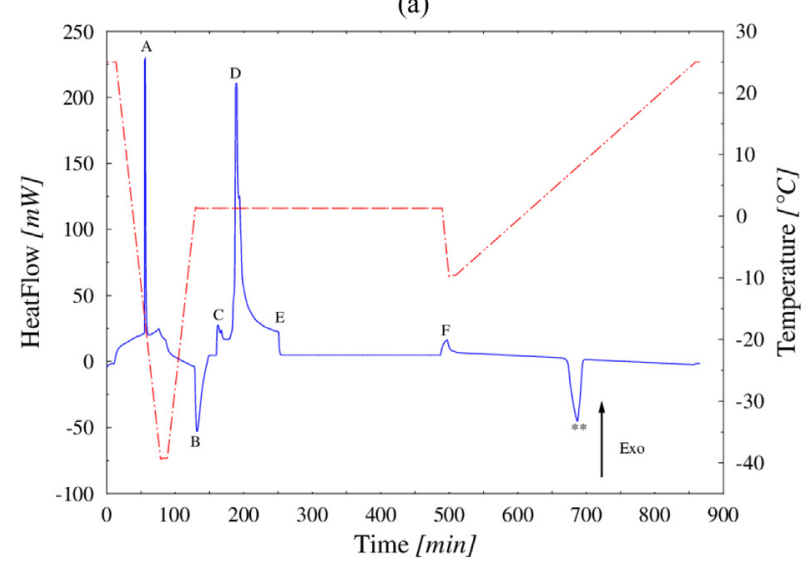

(b)

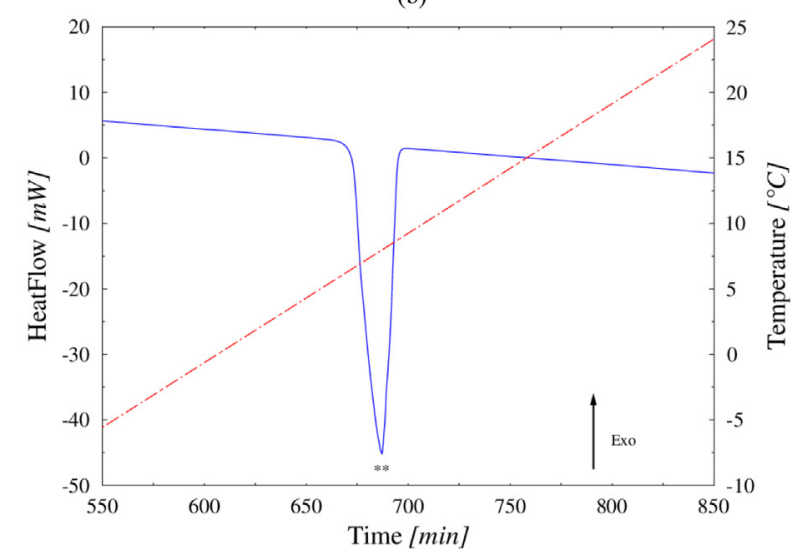

Fig. 8 - Thermogram of a CP hydrate formation experiment with a period of stirring in the cell. Heat flow: full blue line; temperature: dot-dashed red line; symbol ${ }^{* *}$ : CP hydrate dissociation; letters $A$ to $F$ : characteristic events discussed in the text; (a) full thermogram; (b) zoom-in on the last heating cycle.

To the best of the authors' knowledge, only four studies have been found in the literature presenting experimental dissociation enthalpy values for CP hydrates. Zhang et al. (2004) were the first to propose a dissociation enthalpy value for this type of hydrate. Prior to their DSC analysis, they formed a CPin-water emulsion by ultrasonication stabilized by $4 \%$ Tween 85 (polyoxyethylene sorbitan trioleate non-ionic surfactant). They determined a value of $82,300 \mathrm{~J} \mathrm{~mol}^{-1}$ of $\mathrm{CP}$ for the dissociation enthalpy of CP hydrates. Nakajima et al. (2008) published the results of their calorimetric experiments and proposed a new enthalpy value. In their study, they used two different calorimetric techniques (DSC and drop calorimetry) with $\mathrm{CP} /$ water emulsions in the presence of various surfactants. Using DSC, they found a dissociation enthalpy value equal to $284 \mathrm{~J} \mathrm{~g}^{-1}$ of hydrates $\pm 1.1 \%$ (i.e. $106,900 \pm 1200 \mathrm{~kJ} \mathrm{~mol}^{-1}$ of $\mathrm{CP}$ ), which is $\sim 30 \%$ greater than the value reported by Zhang et al. (2004). Drawing on other experimental results obtained by drop calorimetry, and in agreement with the observations of Taylor et al. (2007) (who worked on hydrate-film growth at stationary water/CP interfaces), they suggested a reason to explain the discrepancy with Zhang's value: the bulky CP hydrates might contain unconverted liquid phases. Interestingly enough, drop calorimetry experiments using water/CP systems containing different types and quantities of surfactants produced slightly lower dissociation enthalpy values compared to the ones determined by DSC. They concluded 
that the effective dissociation enthalpy (i.e. the hydrate dissociation enthalpy which takes into account the possible presence of unconverted liquid trapped inside the bulky solid hydrates) depends on the quantity and the nature of the surfactant(s) used to stabilize the emulsion. Accordingly, they estimated that Zhang's value was inaccurate due to the possible presence of unconverted liquid phases in the hydrate phases. Delroisse et al. (2018), published results of DSC experiments carried out with a macro calorimetric cell equipped with an insitu mechanical stirrer using only CP and water (no additive). They determined a dissociation enthalpy of $115,400 \pm 7600 \mathrm{~J}$ $\mathrm{mol}^{-1}$ of CP for the CP hydrates, in perfect agreement with the data of Nakajima et al. (2008). The last study to date was that of Lee et al. (2019) who measured the dissociation enthalpy of CP hydrates using exactly the same protocol, phase ratio, type of additive and additive concentration as Zhang et al. (2004). They found a value of $77,200 \pm 5300 \mathrm{~J} \mathrm{~mol}^{-1}$ of $\mathrm{CP}$, in good agreement with the value obtained by Zhang, but unfortunately, they did not compare their result with the values proposed previously by Nakajima et al. (2008) and Delroisse et al. (2018) which are 38 and $49 \%$ higher than theirs respectively.

Using the data extracted from the thermograms obtained in stirred conditions (see Fig. 8), both the dissociation temperature $\left(\mathrm{T}_{\text {diss }}\right.$ ) of the CP hydrates (onset temperature of the peak) and their dissociation enthalpy value $\Delta \mathrm{H}_{\text {diss }}$ (by integration of the peak) can be obtained. The arithmetic mean of the results obtained from 4 experiments carried out under stirred conditions gives the following robust estimation for the two properties: $\mathrm{T}_{\text {diss }}=6.9 \pm 0.4{ }^{\circ} \mathrm{C}$ and $\Delta \mathrm{H}_{\text {diss }}=109,900$ $\pm 4600 \mathrm{~J} \mathrm{~mol}^{-1}$ of $\mathrm{CP}\left(359 \pm 15 \mathrm{~J} \mathrm{~g}^{-1}\right.$ of water). Our experimental CP-hydrate dissociation temperature value is in perfect agreement with literature data, as the most reliable equilibrium temperature range for these hydrates is considered to be between 6.6 and $7.2^{\circ} \mathrm{C}$ (Ho-Van et al., 2019).The dissociation enthalpy value is also in very good agreement with those of Nakajima et al. (2008) $\left(106,900 \mathrm{~J} \mathrm{~mol}^{-1}\right.$ of CP) and Delroisse et al. (2018) $\left(115,400 \pm 7600 \mathrm{~J} \mathrm{~mol}^{-1}\right.$ of CP), but substantially higher than the values proposed by Zhang et al. (2004) and Lee et al. (2019). In addition to the assumptions given by Nakajima et al. (2008) to explain the difference between their enthalpy value and that of Zhang et al. (2004) (i.e. the presence of unconverted liquid phases in the bulk hydrate phase), we also believe that phenomena related to the additives (e.g. adsorption/desorption of the surfactant, concentration and crystallization of the additive in the remaining liquid phases, etc.) might have been partly responsible for the discrepancies noted between the authors. For example, some properties of the CP hydrates are affected by the presence of surfactants, such as the CP hydrate equilibrium temperature (Baek et al., 2016; Peixinho et al., 2017), crystal morphology (Dicharry et al., 2020; Karanjkar et al., 2012b), zeta potential (Lo et al., 2010) and cohesive force (Aman et al., 2013). Consequently, one might imagine that additives, particularly when they are used at relatively high concentrations (from few $\%$ to $10 \%$ as is the case in some of the previous studies cited in this paper involving water/CP emulsions), might also affect the measurement of the CP hydrates' dissociation enthalpy. This leads us to believe that the dissociation enthalpy value should be determined, where possible, without any additives.

\subsection{2. $\mathrm{CO}_{2}$ hydrates}

Two typical thermograms are presented in Figs. 9 and 10 to highlight the effect of in-situ stirring. Note that reproducibility

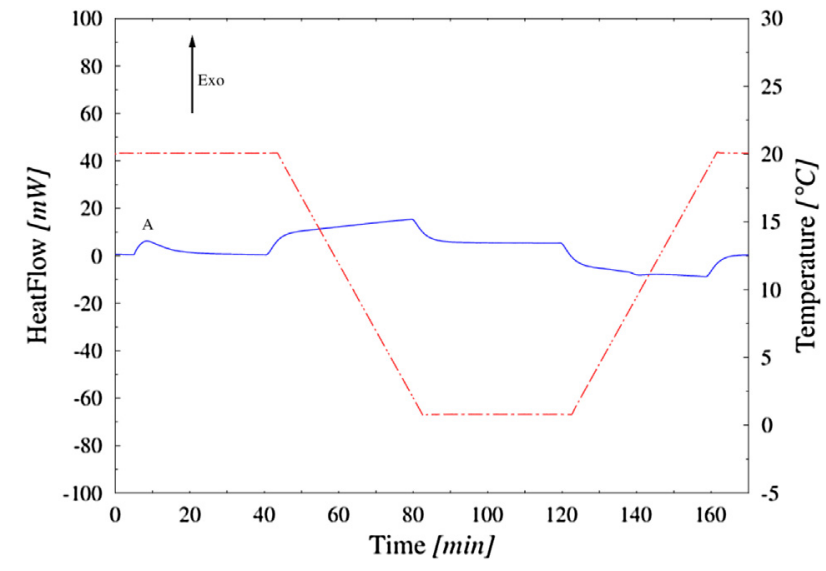

Fig. 9 - Thermograms obtained with water and $\mathrm{CO}_{2}\left(\mathrm{P}_{\mathrm{CO} 2}=\right.$ $33.0 \pm 0.1 \mathrm{bar}$ ) without stirring in the cell. Heat flow: full blue line; temperature: dot-dashed red line; letter $\mathbf{A}$ indicates a characteristic step or event cited in the text.

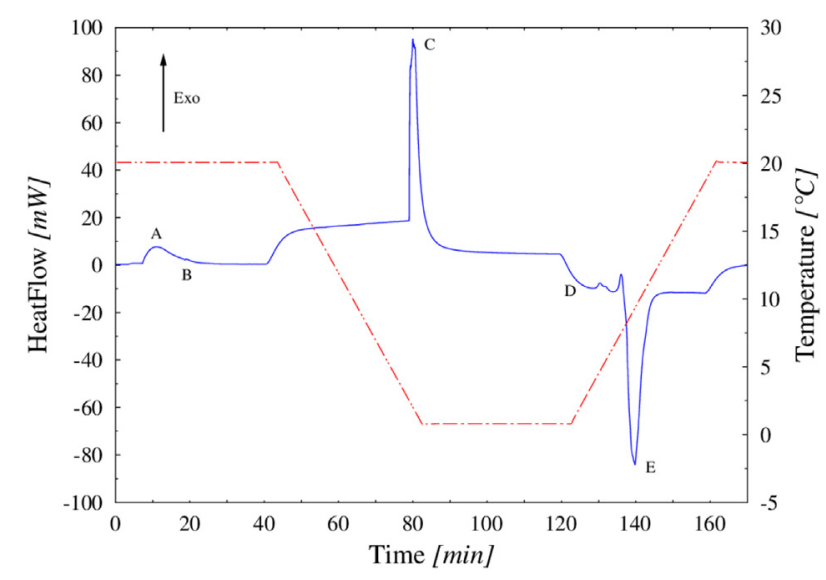

Fig. 10 - Thermograms obtained with water and $\mathrm{CO}_{2}\left(\mathrm{P}_{\mathrm{CO} 2}\right.$ $=33.4 \pm 0.1$ bar) with stirring in the cell. Heat flow: full blue line; temperature: dot-dashed red line; letters A to E: characteristic steps or events cited in the text.

is very good between the different experiments performed in the same conditions, as the same trends were observed for each group of four runs. Two additional thermograms are given in Fig. S3 and S4 of Supporting Information as proof of the good reproducibility of the experiments carried out.

Approximately ten minutes after the experiments were started, the cell was pressurized by $33 \pm 0.5$ bar of $\mathrm{CO}_{2}$ producing the small exothermic peak visible on the heat flow curve at point A in Figs. 9 and 10. The only difference between the two sets of experiments is a period of $100 \mathrm{~min}$ of stirring. In the experiment presented in Fig. 10, this stirring period starts at 20 min (point B) and stops at $120 \mathrm{~min}$ (point D). It should be noted that the decompression and stirrer stopping steps are not shown in the figures.

In quiescent conditions, it can be seen in Fig. 9 that the heat flow variations measured versus time are due only to the typical transient effects that result from changes in the heating sequences (e.g. beginning of the ramp, end of the ramp) but there is no characteristic exothermic peak corresponding to hydrate crystallization. On the contrary, in stirred conditions, Fig. 10 exhibits a strong exothermic peak (point C), observed during the cooling step, that definitely corresponds to $\mathrm{CO}_{2}$ hydrate crystallization as the temperature is always above 0 ${ }^{\circ} \mathrm{C}$. As a logical consequence to the $\mathrm{CO}_{2}$ hydrate crystallization, an endodermic peak is measured during the heating ramp 
which corresponds to the $\mathrm{CO}_{2}$ hydrate dissociation (Fig. 10, point $\mathrm{E})$. The onset temperature of this peak can be used to determine the hydrates' dissociation temperature, which is $8.1 \pm 0.2{ }^{\circ} \mathrm{C}$ for an experimental pressure of $33.4 \pm 0.1$ bar. This result is in very good agreement with the equilibrium point of $\mathrm{CO}_{2}$ hydrates expected in these conditions $(7.8 \pm 0.1$ ${ }^{\circ} \mathrm{C}$ at 33.4 bar according to the CSMGem prediction (Sloan and Koh, 2008)). We have consequently succeeded in answering the three questions that were asked upstream of the experiments: (i) this novel prototype mixing cell works well under pressure and enables the study of gas hydrates; (ii) in-situ stirring triggers the formation of $\mathrm{CO}_{2}$ hydrates even at temperatures above $0{ }^{\circ} \mathrm{C}$; and (iii) as a use case, this apparatus could be used for rapidly acquiring three-phase equilibrium data on gas hydrate systems.

\section{Conclusions}

A novel prototype of a microcalorimetric cell equipped with a mechanical stirrer, suitable for performing analyses under pressure, was designed, constructed and tested. In the experiments conducted, the entire system, which can theoretically withstand pressures of up to 150 bar, was experimentally tested under stirring conditions of up to 44.0 bar of $\mathrm{CO}_{2}$. Typical results obtained during the tests (e.g. pressurized cell, with and without liquid) showed that the rotation of the stirrer in the measuring cell did not affect or disturb the heat flow signal: a perfect baseline was obtained under stirring for all the conditions tested. In addition, experiments performed using an ethanol/water mixture at atmospheric pressure demonstrated that in-situ stirring helps the formation of ice slurry by triggering the crystallization and breaking the high metastability of this system. Experiments were also performed with clathrate hydrate systems. The study of cyclopentane (CP) hydrates at atmospheric pressure also demonstrated the very positive effect of in-situ-stirring for reducing the time of analysis and achieving full water-to-hydrate conversion. We believe that the protocol presented in this study was much simpler than the one involving a preformed emulsion, as the dissociation temperature and enthalpy of the $\mathrm{CP}$ hydrates was easily and rapidly obtained in few hours. A dissociation temperature of $6.9 \pm 0.4{ }^{\circ} \mathrm{C}$ and a dissociation enthalpy of 109,900 \pm $4600 \mathrm{~J} \mathrm{~mol}^{-1}$ of $\mathrm{CP}\left(362 \pm 15 \mathrm{~J} \mathrm{~g}^{-1}\right.$ of water) were obtained for the CP hydrates. Finally, the cell prototype was successfully tested under pressure to study $\mathrm{CO}_{2}$ hydrates: a point on the three-phase equilibrium line of the phase diagram was easily obtained, within a short time and with only one temperature cycle. We consequently believe that this novel micro stirred cell has the potential to open up new avenues in calorimetry, particularly for thermal and DSC analysis of complex systems such as gas hydrates.

\section{Declaration of competing interest}

The authors declare that they have no known competing financial interests or personal relationships that could have appeared to influence the work reported in this paper.

\section{Funding sources}

None.

\section{Acknowledgments}

The authors would like to acknowledge the staff of the Atelier de Physique and J. Diaz from the UPPA for their valuable technical support. This work was supported by the ISIFoR Carnot Institute (sustainable engineering of georesources) which federates academic research dedicated to subsurface energy and environmental issues in Greater Southwest France.

\section{Appendix A. Supplementary data}

Supplementary material related to this article can be found, in the online version, at doi:https://doi.org/10.1016/j.cherd.2020.06.019.

\section{References}

Abojaladi, N., Kelland, M.A., 2016. Can cyclopentane hydrate formation be used to screen the performance of surfactants as LDHI anti-agglomerants at atmospheric pressure? Chem. Eng. Sci. 152, 746-753.

Ahmadi Khoshooei, M., Fazlollahi, F., Maham, Y., Hassan, A., Pereira-Almao, P., 2019. A review on the application of differential scanning calorimetry (DSC) to petroleum products. J. Therm. Anal. Calorim. 138, 3485-3510.

Aman, Z.A., Olctt, K., Pfeiffer, K., Sloan, E.D., Sum, A.K., Koh, C.A., 2013. Surfactant adsorption and interfacial tension investigations on cyclopentane hydrate. Langmuir 29, 2676-2682.

Anwar, S., Carroll, J.J., 2011. Carbon Dioxide Thermodynamic Properties Handbook: Overing Temperatures From $-20^{\circ}$ to $250^{\circ} \mathrm{C}$ and Pressures up to 1000 Bar. John Wiley \& Sons, Inc. Hoboken, New Jersey, and Scrivener Publishing LLC, Salem, Massachusetts

Baek, S., Min, J., Lee, J.W., 2016. Equilibria of cyclopentane hydrates with varying HLB numbers of sorbitan monoesters in water-in-oil emulsions. Fluid Phase Equilib. 413, 41-47.

Bennici, S., Auroux, A., 2009. In: Jackson, by S.D., Hargreaves, J.S.J. (Eds.), Thermal Analysis and Calorimetry Methods, in Metal Oxide Catalysis, vol. 1. Wiley, Weinheim.

Biliaderis, C.G., 1983. Differential scanning calorimetry in food research - a review. Food Chem. 10, 239-265.

Brown, M.E., 2001. Introduction to Thermal Analysis: Techniques and Applications, 2nd ed. Kluwer Academic Publishers, Dordrecht, Boston.

Cai, J., Tao, Y.-Q., von Solms, N., Xu, C.G., Chen, Z.-Y., Li, X.-S., 2019. Experimental studies on hydrogen hydrate with tetrahydrofuran by differential scanning calorimeter and in-situ Raman. Appl. Energy 243, 1-9.

Chong, Z.R., Yang, S.H.B., Babu, P., Linga, P., Li, X., 2016. Review of natural gas hydrates as an energy resource: prospects and challenges. Appl. Energy 162, 1633-1652.

Circone, S., Stern, L.A., Kirby, S.H., Durham, W.B., Chakoumakos, B.C., Rawn, C.J., Rondinone, A.J., Ishii, Y., 2003. $\mathrm{CO}_{2}$ hydrate: synthesis, composition, structure, dissociation behavior, and

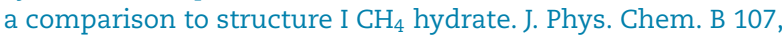
5529-5539.

Daraboina, N., Ripmeester, J., Walker, V.K., Englezos, P., 2011. Natural gas hydrate formation and decomposition in the presence of kinetic inhibitors. 1. High pressure calorimetry. Energy Fuels 25, 4392-4397.

Davies, S.R., Hester, K.C., Lachance, J.W., Koh, C.A., Sloan, E.D. 2009. Studies of hydrate nucleation with high pressure differential scanning calorimetry. Chem. Eng. Sci. 64, 370-375.

Delroisse, H., Torré, J.-P., Dicharry, C., 2017. Effect of a hydrophilic cationic surfactant on cyclopentane hydrate crystal growth at the water/cyclopentane interface. Cryst. Growth Des. 17, 5098-5107.

Delroisse, H., Plantier, F., Marlin, L., Dicharry, C., Froute, L., André, R., Torré, J.-P., 2018. Determination of thermophysical 
properties of cyclopentane hydrate using a stirred calorimetric cell. J. Chem. Thermodyn. 125, 136-141.

Deschamps, J., Dalmazzone, D., 2009. Dissociation enthalpies and phase equilibrium for TBAB semi-clathrate hydrates of $\mathrm{N}_{2}$, $\mathrm{CO}_{2}, \mathrm{~N}_{2}+\mathrm{CO}_{2}$ and $\mathrm{CH}_{4}+\mathrm{CO}_{2}$. J. Therm. Anal. Calorim. 98, 113-118.

Deschamps, J., Dalmazzone, D., 2010. Hydrogen storage in semiclathrate hydrates of tetrabutyl ammonium chloride and tetrabutyl phosphonium bromide. J. Chem. Eng. Data 55, 3395-3399.

Dicharry, C., Delroisse, H., Torré, J.-P., Barreto, G., 2020. Using microscopic observations of cyclopentane hydrate crystal morphology and growth patterns to estimate the anti-agglomeration capacity of surfactants. Energy Fuels 34, 5176-5187, http://dx.doi.org/10.1021/acs.energyfuels.9b03395, In press.

Egenolf-Jonkmanns, B., Janicki, G., Bruzzano, S., Deerberg, G., Dalmazzone, D., Fürst, W., 2017. Experimental study on the influence of hydrogel on $\mathrm{CO}_{2}$ hydrate formation. Chem. Ing. Tech. 89, 733-742.

El Abbassi, I., Castaing-Lasvignottes, J., Bedecarrats, J.-P., Dumas, J.-P., Mimet, A., 2010. Energetic performances of a refrigerating loop using ice slurry. Appl. Therm. Eng. 30, 962-969.

El Abbassi, I., Darcherif, A.M., Lasvignottes, J.-C., 2014. The energetic performance analysis of the coupling between the production and distribution of an ice slurry loop. In: Proc. of 1st International Conference on Green Energy, ICGE 2014, 25-27 March 2014, Sfax, Tunisia, pp. 77-81.

Flick, E.W., 1998. Industrial Solvents Handbook, fifth edition. Noyes Data Corporation (ndc), Westwood, NJ.

Fouconnier, B., Komunjer, L., Ollivon, M., Lesieur, P., Keller, G., Clausse, D., 2006. Study of $\mathrm{CCl}_{3} \mathrm{~F}$ hydrate formation and dissociation in W/O emulsion by differential scanning calorimetry and X-ray diffraction. Fluid Phase Equilib. 250, 76-82.

Gholinezhad, J., Chapoy, A., Tohidi, B., 2011. Separation and capture of carbon dioxide from $\mathrm{CO} 2 / \mathrm{H} 2$ syngas mixture using semi-clathrate hydrates. Chem. Eng. Res. Des. 89, 1747-1751.

Haynes, W.M., 2013. CRC Handbook of Chemistry and Physics, 94th edition. CRC Press LLC, Boca Raton, FL.

Ho-Van, S., Bouillot, B., Douzet, J., Maghsoodloo Babakhani, S., Herri, J.-M., 2019. Cyclopentane hydrates - a candidate for desalination? J. Environ.Chem. Eng. 7, 103359.

Karanjkar, P.U., Lee, J.W., Morris, J.F., 2012a. Calorimetric investigation of cyclopentane hydrate formation in an emulsion. Chem. Eng. Sci. 68, 481-491.

Karanjkar, P.U., Lee, J.W., Morris, J.F., 2012b. Surfactant effects on hydrate crystallization at the water-oil interface: hollow-conical crystals. Cryst. Growth Des. 12, 3817-3824.

Kauffeld, M., Wang, M.J., Goldstein, V., Kasza, K.E., 2010. Ice slurry applications. Int. J. Refrig. 33, 1491-1505.

Kay, W.B., 1947. Vapor pressures and saturated liquid and vapor densities of cyclopentane, methylcyclopentane, ethylcyclopentane and methylcyclohexane. J. Am. Chem. Soc. 69, 1273-1277.

Koh, C.A., Sloan, E.D., Sum, A.K., Wu, D.T., 2011. Fundamentals and applications of gas hydrates. Annu. Rev. Chem. Biomol. Eng. 2, 237-257.

Kumar, A., Sakpal, T., Linga, P., Kumar, R., 2015. Enhanced carbon dioxide hydrate formation kinetics in a fixed bed reactor filled with metallic packing. Chem. Eng. Sci. 122, 78-85.

Kumar, A., Kumar Yadav, S., Mahato, A., Kumar, A., 2019. On-demand intermittent ice slurry generation for subzero cold thermal energy storage: numerical simulation and performance analysis. Appl. Therm. Eng. 161, 114081.

Le Parlouër, P., Dalmazzone, C., Herzhaft, B., Rousseau, L., Mathonat, C., 2004. Characterisation of gas hydrates formation using a new high pressure micro-DSC. J. Therm. Anal. Calorim. 78, 165-172.

Lee, J., Kim, K.-S., Seo, Y., 2019. Thermodynamic, structural, and kinetic studies of cyclopentane $+\mathrm{CO}_{2}$ hydrates: applications for desalination and $\mathrm{CO}_{2}$ capture. Chem. Eng. J. 275, 121974.
Li, G., Liu, D., Xie, Y., 2010. Study on thermal properties of TBAB-THF hydrate mixture for cold storage by DSC. J. Therm. Anal. Calorim. 102, 819-826.

Lo, C., Zhang, J.S., Couzis, A., Somasundaran, P., Lee, J.W., 2010. Adsorption of cationic and anionic surfactants on cyclopentane hydrates. J. Phys. Chem. C. 114, 13385-13389.

Martinez, M.C., Dalmazzone, D., Fürst, W., Delahaye, A., Fournaison, L., 2008. Thermodynamic properties of $\mathrm{THF}+\mathrm{CO}_{2}$ hydrates in relation with refrigeration applications. AIChE J. 54, 1088-1095.

Muravyeva, N.V., Monogarov, K.A., Bragin, A.A., Fomenkov, I.V., Pivkin, A.N., 2016. HP-DSC study of energetic materials. Part I. Overview of pressure influence on thermal behaviour. Thermochim. Acta 631, 1-7.

Nakajima, M., Ohmura, R., Mori, Y.H., 2008. Clathrate hydrate formation form cyclopentane-in-water emulsion. Ind. Eng. Chem. Res. 47, 8933-8939.

Oignet, J., Delahaye, A., Torré, J.-P., Dicharry, C., Hoang, H.-M., Clain, P., Osswald, V., Youssef, Z., Fournaison, L., 2017. Rheological study of $\mathrm{CO}_{2}$ hydrate slurries in the presence of Sodium Dodecyl Sulfate in a secondary refrigeration loop. Chem. Eng. Sci. 158, 294-303.

Pecchi, M., Patuzzi, F., Benedetti, V., Di Maggio, R., Baratieri, M., 2020. Thermodynamics of hydrothermal carbonization: assessment of the heat release profile and process enthalpy change. Fuel Process. Technol. 197, 106206.

Peixinho, J., Ageorges, V., Duchemin, B., 2017. Growth of clathrate hydrates from water drops in cyclopentane. Energy Fuels, $7 \mathrm{~b} 02740$.

Plantier, F., Marlin, L., Missima, D., Torré, J.-P., 2013. Development of a new type of high pressure calorimetric cell, mechanically agitated and equipped with a dynamic pressure control system - application to the characterization of gas hydrates. Rev. Sci. Instrum. 84, 125107.

Sales Silva, L.P., Dalmazzone, D., Stambouli, M., Arpentinier, P., Trueba, A., Fürst, W., 2016. Phase behavior of simple tributylphosphine oxide (TBPO) and mixed gas $\left(\mathrm{CO}_{2}, \mathrm{CH}_{4}\right.$ and $\left.\mathrm{CO}_{2}+\mathrm{CH}_{4}\right)+$ TBPO semiclathrate hydrates. J. Chem. Thermodyn. 102, 293-302.

Shao, X.-F., Chen, C.-L., Yang, Y.-J., Ku, X.-K., Fan, L.-W., 2019. Rheological behaviors of sugar alcohols for low-to-medium temperature latent heat storage: effects of temperature in both the molten and supercooled liquid states. Sol. Energy Mater. Sol. Cells 195, 142-154.

Sloan, E.D., Koh, C.A., 2008. Clathrate Hydrates of Natural Gases, 3rd ed. CRC Press, New York.

Sum, A.K., Koh, C.A., Sloan, E.D., 2009. Clathrate hydrates: from laboratory science to engineering practice. Ind. Eng. Chem. Res. 48, 7457-7465.

Taylor, C.J., Miller, K.T., Koh, C.A., Sloan, E.D., 2007. Macroscopic investigation of hydrate film growth at the hydrocarbon/water interface. Chem. Eng. Sci. 62, 6524-6533.

Torré, J.-P., Haillot, D., de Souza, Rigal S., Lima, R.W., Dicharry, C., Bedecarrats, J.-P., 2015a. 1,3 dioxolane versus tetrahydrofuran as promoters for $\mathrm{CO}_{2}$-hydrate formation: thermodynamics properties, and kinetics in presence of sodium dodecyl sulfate. Chem. Eng. Sci. 126, 688-697.

Torré, J.-P, Plantier, F., Marlin, L., 2015. High-pressure calorimetric measurement cell, 23 July 2015, patent \# US 14/417,313.

Turi, E.A., 1997. Thermal Characterization of Polymeric Materials (second Edition). Academic Press, San Diego.

Uchida, T., 1997. Physical property measurements on $\mathrm{CO}_{2}$ clathrate hydrates. Review of crystallography, hydration number, and mechanical properties. Waste Manage. 17, 343-352.

Uchida, T., Hondoh, T., Mae, S., Kawabata, J., 1995. Physical data of $\mathrm{CO}_{2}$ hydrate. In: Handa, N., Ohsumi, T. (Eds.), Direct Ocean Disposal of Carbon Dioxide. Terra Scientific Publishing Company, Tokyo, pp. 45-61.

Vaessen, R.J.C., Janse, B.J.H., Seckler, M.M., Witkamp, G.J., 2003. Evaluation of the performance of a newly developed eutectic freeze crystallizer: scraped cooled wall crystallizer. Chem. Eng. Res. Des. 81, 1363-1372. 
Yalkowsky, S.H., He, Y., Jain, P., 2010. Handbook of Aqueous Solubility Data, 2nd ed. CRC Press, Boca Raton, FL, pp. 158.

Zhang, Y., Debenedetti, P.G., Prud'homm, R.K., Pethica, B.A., 2004. Differential scanning calorimetry studies of clathrate hydrate formation. J. Phys. Chem. B 108, 16717-16722.
Zhong, D.-L., Wang, W.-C., Zou, Z.-L., Lu, Y.-Y., Yan, J., Ding, K., 2018. Investigation on methane recovery from

low-concentration coal mine gas by tetra-n-butyl ammonium chloride semiclathrate hydrate formation. Appl. Energy 227, 686-693. 